\title{
Strates
}

STRATES Matériaux pour la recherche en sciences sociales

$10 \mid 2001$

Villageois et citadins de Grèce

\section{De l'objet ethnologique à l'objet littéraire : la conversion risquée}

Stathis Damianakos

\section{(2) OpenEdition}

1 Journals

Édition électronique

URL : http://journals.openedition.org/strates/384

DOI : $10.4000 /$ strates.384

ISSN : $1777-5442$

Éditeur

Laboratoire Ladyss

Édition imprimée

Date de publication : 1 mai 2001

ISSN : 0768-8067

\section{Référence électronique}

Stathis Damianakos, " De l'objet ethnologique à l'objet littéraire : la conversion risquée ", Strates [En ligne], 10 | 2001, mis en ligne le 12 janvier 2005, consulté le 23 septembre 2020. URL : http:// journals.openedition.org/strates/384 ; DOI : https://doi.org/10.4000/strates.384

Ce document a été généré automatiquement le 23 septembre 2020.

Tous droits réservés 


\title{
De l'objet ethnologique à l'objet littéraire : la conversion risquée
}

\author{
Stathis Damianakos
}

Jacques LACARRIÈRE et Michel VOLKOVITCH

La Grèce de l'ombre, Anthologie des chants rébétika

Christian Pirot, 1999, $161 \mathrm{p}$.

4 Apparus vers la fin du XIX siècle et en création permanente tout au long de la première moitié $\mathrm{du} \mathrm{XX}^{\mathrm{e}}$, les rébétika grecs résument la poétique des marginaux et des déracinés qui affluent pendant cette période dans les grandes villes ou les ports de part et d'autre de la mer Egée. Souvent comparés aux urban blues américains, au tango argentin ou au fado portugais, ils disent la solitude, l'errance, l'exil, le mal de vivre et d'aimer du laissé-pour-compte de la société contemporaine, mais aussi sa fierté, sa quête de dignité et sa révolte contre le sort qu'on lui fait subir. Comme ceux-ci, ils sont nés dans des lieux malfamés que fréquente la «pègre " urbaine : tavernes, fumeries de haschisch, prisons, cabarets ou maisons de tolérance. À leur instar, ils feront l'objet du mépris le plus total de la part de la société bien pensante ainsi que de multiples interdictions policières qui les contraindront à vivre, pendant longtemps, dans une situation de quasi-clandestinité. Comme eux, enfin, à un certain moment de leur parcours historique, ils seront « découverts » par des élites nationales à la recherche de nouveaux sons, d'exotisme et de spontanéité, découverte qui les transformera en chansons à la mode tout en les vidant de leur sémantique sociale. Pris en charge par l'industrie du disque, irrémédiablement falsifiés aussi bien dans leur forme que dans leur symbolique, ils disparaîtront définitivement dans les années cinquante. Depuis, leur destin est scellé par l'ambiguïté fondamentale qui accompagne toutes les entreprises de récupération culturelle de la création orale (on l'avait déjà vue d'ailleurs à propos du chant clephtique) : qu'il s'agisse d'arrangements musicaux et littéraires ou de soi-disant "études » menées dans l'esprit de l'école ethnographique grecque, la perception du rébétiko oscille constamment entre la reconnaissance de sa profonde altérité sociale et le souci d'affirmer à travers lui l'identité nationale. Fallait-il l'admettre comme expression privilégiée des bas-fonds et des « a-sociaux » des centres 
urbains ou le considérer comme incarnation par excellence de l'ethos du néo-hellène ? Il est évident que la seule voie pour lever la contradiction est celle qui fut effectivement suivie, à savoir la folklorisation de ces chants, l'aliénation de leur surface signifiante par rapport à leur signifié, leur métamorphose en mythe contemporain.

Présentée dans un petit volume élégant agrémenté d'annotations et de dessins, la traduction par Jacques Lacarrière et Michel Volkovitch d'une centaine des rébétika célèbres, composés essentiellement depuis les années vingt jusqu'à l'immédiat aprèsguerre, n'échappe pas à cette ambiguïté. À commencer par le titre de l'ouvrage : La Grèce de l'ombre (formule qui, malgré les affirmations lénifiantes de Jacques Lacarrière, en dit long sur l'étrangeté dévalorisante de l'objet) défère mal à la vision ethnoromantique du " philhellène ", admirateur de la "Grèce éternelle ", toujours prompt à s'extasier devant un vocable de l'argot populaire qu'il a déjà rencontré chez Hérodote ou Sophocle. Mais il y a plus. Dans quelle mesure l'entreprise d'adaptation dans une langue étrangère des œuvres de la tradition orale n'appartient-elle pas au domaine de l'impossible, ne relève-elle pas, pour reprendre les propos de Michel Volkovitch, « de l'opération suicide»? Au-delà des raisons invoquées ou suggérées (séparation arbitraire entre paroles et musique, réduction d'une création faite pour être entendue à un texte à lire, polysémie inhérente du langage populaire), a-t-on le droit d'éluder la question de la légitimité même de la conversion d'un objet ethnologique en objet littéraire ? Choisir de présenter en français tel chant plutôt que tel autre soit en raison de sa "valeur " poétique, soit pour son exotisme insolite apte à "épater le bourgeois ", soit, simplement, parce qu'il s'offre plus docilement au travail de traduction, c'est prendre le risque de déformer gravement l'esprit de ces créations. Ne sait-on pas qu'en matière de tradition orale la dimension « esthétique » de l'œuvre est inextricablement imbriquée dans sa sémantique sociale globale?

Dans un domaine voisin, celui de l'organisation de par le monde des musées dits « d'art populaire ", l'exemple des objets exposés (choisis selon le seul critère de leur " beauté » ou de leur " singularité ») est de ce point de vue instructif. Détachés de leur contexte, amputés de leur fonctionnalité sociale, irrémédiablement appauvris dans leur sens et dans leur symbolique, ils font naître le sentiment chez le visiteur qu'ils ne sont là sagement couchés derrière leurs vitrines - que pour confirmer la domination de la culture bourgeoise sur toutes les autres ou pour évoquer l'acte fondateur de leur constitution en curiosités exposables: le pillage. Le regard porté par la littérature savante sur la poésie populaire n'est pas foncièrement différent. Faute de connaître à fond l'éthique et la culture du milieu concerné, l'intervention du philologue a de fortes chances de reproduire le discours de l'ethnologie traditionnelle (eurocentrique et colonialiste), à savoir le "récit-voyage " et le "récit-adaptation ». Il n'y a eu, à ma connaissance, qu'une seule opération réussie dans ce domaine bondé de pièges plus redoutables les uns que les autres : l'adaptation en français des Negro spirituals par M. Yourcenar parue en 1964 chez Gallimard. Mais tout le monde sait par quel travail acharné de documentation (portant aussi bien sur l'époque que sur le milieu) la grande dame des lettres françaises faisait précéder la composition du moindre de ses écrits.

Le recueil publié par Jacques Lacarrière et Michel Volkovitch contient incontestablement de bons moments, on pourrait même dire que, parfois, le souffle passe. Mais, en contrepartie, que de simplifications abusives, que de généralisations hâtives, que de maladresses inexcusables de la part de deux écrivains réputés pourtant fins connaisseurs de la culture grecque contemporaine! Comment interpréter, par 
exemple, le croquis de la couverture représentant deux danseurs qui se tiennent par la main (figure de danse typiquement paysanne, puisque les rébétès dansaient soit seuls, soit en se tenant par les épaules), sinon comme la preuve d'un regard désinvolte sur le monde rébétique et sa symbolique ? À cela il faut ajouter l'arbitraire du choix des textes, le caractère plutôt fantaisiste des annexes ainsi que les nombreux faux pas dans la "Présentation", les «Remarques» ou les annotations qui accompagnent les traductions : la silhouette du rébétis n'a rien d'un " paumé » ou d'un «SDF » (d'ailleurs elle disparaît du paysage urbain à partir des années soixante), la bourgeoisie athénienne ne commence pas à s'intéresser au rébétiko dans les années soixante-dix, son engouement pour ce chant est bien antérieur, le tékès (fumerie de haschisch) est loin d'être synonyme de la taverne de même que le dounias (qui signifie monde, œcumène) (p. 12). En outre, la naïveté de certains commentaires (tel celui qui explique le désespoir d'un rébétis cherchant à mettre fin à sa vie par le fait que « apparemment cet homme n'a pas connu de femme» (!...) - cf. «Dans la mer», p. 25), le détournement manifeste du sens de certains textes mal compris (comme c'est le cas de l'admirable "Charos est sorti pour pêcher », p. 69), ou la perception, hors contexte, de certaines expressions populaires (le mot «sympathie» par exemple évoqué dans le «Petit boucher » que l'auteur trouve « très plat », p. 143, oubliant que dans l'éthique populaire de l'époque les vocables " amour ", " éros » ou " passion » sont proscrits), ne font que confirmer le lecteur dans son sentiment qu'il s'agit là d'un travail ignorant superbement toute source ou documentation existante sur la question.

8 La bibliographie rébétique est assez riche en grec, quant à la bibliographie française ou anglo-saxonne, elle n'est pas aussi inexistante que le prétendent les auteurs.

Il suffit de la chercher. 